\title{
A Study on the Ex-ante Evaluation on Government R\&D Programs Using Fuzzy Reasoning
}

\author{
Yoon Been Lee*
}

\begin{abstract}
In 2007, the Korean government officially introduced an ex-ante evaluation system, the preliminary feasibility study (PFS), for supporting the decision making process that informs R\&D investment budgets, which uses economic, policy, and technological criteria to evaluate prospective R\&D programs. From an analytical perspective, this kind of balanced assessment is very important in budget allocation decision making and thus the need for objective quantitative values that can lead to a conclusive judgment on the status of an $R \& D$ investment has been growing.

However, owing to measurement problems and a lack of information, PFSs as well as economic feasibility assessments, a critical subdimension of PFSs, have faced difficulties in deriving a satisfactory single assertive conclusive value. Furthermore, the emphasis on expected economic returns of the R\&D investment from the perspective of long-term national strategy in PFSs seems to contradict the original intention of ex-ante evaluation system, which is supposed to take not only economic but also technological and policy dimensions into account independently.

The aim of this study is to investigate the question of independency in PFSs, especially in the assessment of economic feasibility raised by many critics. If there are some systematic connections between assessments of other dimensions of feasibility and the economic one, it becomes hard to sustain the basic assumption of the PFS, and we need to explicitly take this linkage into account in performing PFSs. To verify the existence of this connection, I propose a method to derive pseudovalues that provide an economic assessment of the R\&D program from those originally derived via analyses: a method of a fuzzy reasoning approach that converts experts' judgments into systematic calculations. Furthermore, I suggest that the results generated by fuzzy reasoning can be used to complement a traditional economic analysis, since fuzzy reasoning can inform the development of a comprehensive structure for ex-ante evaluation for government programs.
\end{abstract}

Keywords: government R\&D program, ex-ante evaluation, preliminary feasibility study, fuzzy reasoning, multi-criteria analysis

* R\&D Feasibility Analysis Center, Korea Institute of S\&T Evaluation and Planning, 9F Dongwon Industries Bldg. 68 Mabang-gil, Seocho-gu, Seoul, 137-717, Korea. E-mail: yblee@kistep.re.kr.

Manuscript received October 10, 2013; out for review October 20, 2013; review completed December 16, 2013; accepted December 18, 2013.

The Korean Journal of Policy Studies, Vol. 28, No. 3 (2013), pp. 77-96.

(C) 2013 by the GSPA, Seoul National University 


\section{INTRODUCTION}

Public investment is necessary when national or local public organizations want to accomplish public goals such as increasing employment or public welfare. If Pareto efficiency is not achieved through the principal activities in the market alone, governmental interventions are in general required to correct market failures as well as to increase social welfare by solving the problems associated with the externalities.

For these purposes, a government is supposed to incorporate analyses of the various public investment criteria such as efficient resource allocation, equal income redistribution, and economic stability, into the decision-making process in democratic way. The government of South Korea took a step in this direction in 1977 by setting up ex-ante evaluation rules for major investment programs supervised by the Economic Planning Board (EPB), a central government agency. Since then, these ex-ante rules have been revised many times in light of prevailing socioeconomic circumstances.

Government R\&D programs (GRPs) are one type of government investment program, defined as programs in the fields of science and technology that are specified, regulated, and funded by the government. The budgets for GRPs are derived from general or special accounts of the annual budget, and ever since the establishment of formal GRPs in South Korea in 1982, the size of the programs has soared; for instance, in 1999, the government spent USD\$3.1 billion on 197 programs but by 2008, the government was spending USD $\$ 9.8$ billion on 457 programs. This rapid increase in the GRPs budget has made it necessary to establish more efficient and effective systems for allocation, control, and evaluation.

A preliminary feasibility study (PFS) system was designed in 2008 to examine the feasibility of GRPs with budgets of over USD $\$ 4.4$ million through multiple criteria, such as technical, economic, and policy relevance, and the results were used to streamline and improve the investment decision-making process of the GRPs. This system has been carried out by special research teams with professional backgrounds in managing the multidisciplinary nature of GRPs and in making objective assessments of public investment. ${ }^{1}$

But the system has faced many difficulties from its inception. One of the persistent difficulties in implementing the PFS has been a dearth of relevant information for assessing economic feasibility. For instance, economic feasibility is assessed by comparing the costs and benefits of the proposed program. In cases where market values are available, then the expected costs and benefits are calculated as monetary values,

1. Ministry of Strategy and Finance, operating instructions on preliminary feasibility study, 2009. 
and a single benefit/cost $(\mathrm{B} / \mathrm{C})$ ratio can be calculated for rating the economic feasibility. ${ }^{2}$ If no information from the real or a surrogate market is available, however, a stated preference approach is used that extracts the information by presenting a virtual market to potential consumers and asking them how willing they would be to pay for each component of the market .

But the stated preference approach has been criticized on numerous grounds. First, it is difficult to provide an appropriate explanation of what exactly GRPs are to survey participants. Second, if the $\mathrm{B} / \mathrm{C}$ ratio is derived as range rather than single value, then further information for rating economic feasibility is still needed. ${ }^{3}$ Third, economic feasibility is supposed to be assessed independently of other dimensions such as technological and policy feasibilities, but its assessment seems to be influenced by the feasibility assessments of other dimensions due to a chronic lack of relevant information. In this case, the basic assumption of the PFS, independency, will be violated and the result of the economic feasibility assessment cannot be regarded as its own value. Owing to the critical importance of economic feasibility in budget allocation decision making (it accounts for around 30 to 50 percent of the overall weight in a PFS), there are both logical and practical reasons why this problem cannot be disregarded. ${ }^{4}$

This study investigates an analytical aspect of the economic rating method of the PFS when there are fundamental limitations on economic information. As mentioned before, if economic feasibility is not assessed independently from other dimensions, we cannot assure the validity of the PFS, which was originally designed to allow for balanced decision making in light of the multidimensionality of GRPs. In this line, I present and verify a dependency of PFSs of GRPs using fuzzy reasoning, drawing on the concepts of the fuzzy expert system and a program logic model that regards the expected benefits as an output of stepwise progress of GRPs. For empirical data, I rely on the real results of PFSs and prefeasibility studies of GRPs, which were conducted before 2008, when PFSs replaced them.5

2. Construction programs, for example, take the values derived from the cost-benefit analysis and convert the values into ratings.

3. Sometimes effectiveness rather than benefits or costs is derived when valuation is not feasible.

4. Ministry of Strategy and Finance, operating instructions on preliminary feasibility study, 2009.

5. The average budget for the 51 cases was USD $\$ 518.4$ million, and the average program period was eight years. Among them, 42 cases are the results of PFSs with USD\$591.9 million of the average budget over an average period of 7.9 years, and 9 cases are the results of pre-feasibility studies with USD $\$ 175.1$ million of the average budget over an average period of 8.2 years. 
The paper is organized as follows. I first provide the theoretical background of the ex-ante evaluation system of GRPs and present the theoretical frame for the analysis in the next section. Fuzzy inference is proposed as an analytical framework, and a presentation of empirical results and discussion is followed with a consideration of possible variations of $R \& D$ types and methods of economic assessment. In concluding, I suggest the method as a complementary tool for improving the functions of PFSs of GRPs when extracting information about economic benefits using economic theory faces significant limitations or is even impossible.

\section{THEORETICAL BACKGROUND}

\section{Lack of Economic Information}

Although a cost-benefit analysis was first used in connection with a public project in 1844 by the French economist Jules Dupuit, it wasn't until the 1940s that it was conceptualized by the Italian economist Vilfredo Pareto and British economists Nicholas Kaldor and John Hicks in 1940s. It was then used to assess the feasibility of programs such as water resources development and researched as a proper means of carrying out ex-ante evaluations of public-funded programs (Kim, 2004). Despite its popularity, however, it is a difficult method of analysis because in order to make reliable and accurate predictions, abundant information and detailed program plans that track progress are required.

Furthermore, the degree of difficulty in estimating costs as opposed to benefits is not equal. Many methods for estimating the costs of research equipment or facilities have been proposed and applied in the fields of space and aviation research, and there are also stable and reliable methods for estimating the personnel costs occupying the majority part of pure research (Yang, 2007). ${ }^{6}$ Estimating benefits, however, proves more challenging. Economic benefits of a given GRP should be estimated using a sequence of calculations that targets each of the multidimensional segments that make up the GRP. In addition, these various segmented benefits have to be analyzed simultaneously within a limited time. Due to these difficulties, there is a higher likelihood that the calculations of segmented benefits in the analysis will overlap or that a calculation will be omitted altogether, even if caution is taken.

But a more challenging problem stems from lack of information. In general, if

6. "Pure research" refers to research activities that can be done without a lot of equipment or that don't require facilities. 
demand and unit price can be estimated, benefits can be calculated in a relatively easy manner. However, in the case of public investment, there is usually no market information on demand or unit price. Therefore, revealed or stated preference approaches, for instance, have been explored but, as mentioned before, these approaches have not proved satisfactory yet in either making judgments or quantifying measures.

Another difficulty in the measurement of benefits arises from the intrinsically uncertain relationship between investment and performance effected by the existence of various paths of benefit creation, by the fact that benefits have diverse recipients, and by the quantification of benefits on a monetary scale (OECD, 2007). This is why various methods for estimating benefits from R\&D are suggested in practice, such as production function with total factor productivity, real options (Hwang, 2004), performance analysis, network patent analysis, scenario building, and analysis of the contribution of R\&D investment to industry and to the creation of knowledge.

Finally, not the least difficulty is that some economic benefits from R\&D programs are not produced during a predefined, specific period. The amount of time necessary to realize a benefit is referred to as the gestation period (Yang, 2010), which represents the delay between when the GRP investment is made and the economic benefit accrues. ${ }^{7}$ Mansfield (1991), for instance, analyzed the amount of time necessary for academic research to lead to the commercialization of new products or processes and showed that it took on average 7 years for basic research and 6.4 years in the case of applied technology development. In short, it is hard to define a typical gestation period to estimate the expected benefits for various types of GRPs.

\section{Multicriteria Analysis}

The result of the PFSs of GRPs is used to arrive at a final decision for public investment (yes or no). This decision-making process sets the criteria and assigns quantitative values of weight for each in order to rank the appropriateness of all the alternatives in terms of technical, policy and economic importance: alternatives of feasible and unfeasible. To combine the differences in the importance of various dimensions of PFSs, the analytic hierarchy process (AHP) method, which derives a result from the eigenvector of a pairwise comparison matrix across alternatives or different criteria, is applied. The best alternative is thus represented by the sum of the weighted values.

7. The term "gestation period" can be variously used to refer to the time delay in R\&D-related literature. 


$$
\begin{aligned}
& \sum_{i=1}^{n} a_{i j}=1 \\
& A_{A H P-s c o r e}=\max _{i} \sum_{j=1}^{n} a_{i j} w_{i}
\end{aligned}
$$

for $i=1,2, \ldots, m$

The AHP method yields a quantitative form reflecting the relative importance or degree to which each dimension is preferred. Because the method can be concisely applied and because of the mathematical clarity of its measurement system, weight calculation, and inconsistency test, the AHP method is highly valued (Park, 2000) and widely used in various fields. ${ }^{8}$

In order to maintain institutional consistency, the AHP method in PFSs of GRPs use similar structures and criteria to analyze each dimension of an R\&D program. Although economic relevancy is critical, it is a basic dimension, and other dimensions (technology and policy relevancy) play important roles in the final decision making. In other words, each dimension should be balanced and have its own independent value. This is what I aim to investigate here with a new approach, fuzzy theory.

\section{Fuzzy Sets and Fuzzy Inference Control}

Fuzzy aggregation theory was first introduced in the mid-1960s by Chang and Zadeh (1972). It is a mathematical theory for modeling ambiguous and unclear properties such as human cognitive processes. Whereas an accurate value (or crisp value) has a single clear interpretation, a fuzzy value is ambiguous and thus it can be analyzed in different ways. For instance, each fuzzy set has a degree of membership value between 0 and 1 . If the comprehensive set of fuzzy numbers is a finite set, it is expressed as a discrete type. Otherwise, it is expressed as a continuous type. Continuous types can be formed into different shapes such as triangles, trapezoids, bell shapes, and Gaussian

8. For example, Rosnah and colleagues (2001) examined the possibilities of using AHP to evaluate advanced manufacturing technology, Priyantha and colleagues (2006) used AHP to prioritize obstacles in the strategic planning process regarding renewable energy, and Ramanathan (2002) applied AHP in the process of connecting the technology for reducing greenhouse gases with the regional needs of developing countries. Cho Keun-Tae and Kwon Cheol-Shin (2004) have advocated the use of an advanced model of AHP reflecting cross-impact in order to prioritize correlated technologies. 
shapes.

Since the 1970s there have been studies on fuzzy control, which consists of fuzzy sets and fuzzification, a rule base, and defuzzification. Fuzzification is the process of converting variables into membership functions. In other words, the result of the fuzzification can be displayed as a set of diagrams that expresses the degree of membership of fuzzy variables. The range and shape of a membership function can then be defined based on the system requirements and the experience of the developer. In case of policy problems, experts' opinions or the analysis of past resources can be used to elaborate the membership function.

Since Mamdani's formulation of fuzzy inference (1974), many practical applications of fuzzy theory have been found in home appliances, medical devices, chemicals, electric power, aviation, aerospace, industrial electronics, automation systems, and information technology. In recent years, fuzzy rules have become more flexible, allowing fuzzy logic to be applied to nonlinear systems and cases in which information is inadequate due to uncertainty, errors, and imperfection of the situation (Lee, 1996).

Because of the simplicity of structuring expert judgments and the ease of incorporating new information or updating old information, the scope of fuzzy control's application has widened from physical systems to customer service, diagnosis of current status, measurement of service levels, and calculation of corporate credit rating following changes in financial structure. There are few previous cases, however, of applying fuzzy sets and fuzzy reasoning to decision making regarding public investment, which is subject to various risk factors and for which little information is available.

\section{ANALYTICAL FRAMEWORK}

\section{Selection of the Fuzzy Variables}

I begin by building a model for fuzzy reasoning using supplementary data to analyze the suitability of economic ratings. The strategy I take is to compare values derived from fuzzy reasoning based on results of PFSs that analyzed logical and technological criteria of GRPs with the actual values of economic ratings based on cost-benefit analyses. If the set of former values are close enough to that of the latter, we can conclude that there is a low likelihood that the assessments of the discrete dimensions of a GRP are independent of each other because it is unrealistic to expect the closeness to be consistent along the more than 50 previous PFS results. I also analyze possible variations of the relationship with respect to $\mathrm{R} \& \mathrm{D}$ program types or methods of economic analysis in order to check the robustness of this reasoning. 
In PFSs of GRPs, relative weights are allocated to eight criteria and assessment scores are assigned to each criterion based on the analyses related to it. For logical criteria, a logic model for R\&D programs is employed, and for technological criteria, technological viability assessments are examined in order to derive the factors that distinguish the prospective success of the GRPs from failure.

The logic model for an R\&D program, reflecting the logical structure of a program plan and its management, consists of various elements such as planning processes, program objectives, management systems, and extensive documentation of research activities. ${ }^{9}$ The more precise the information and the more organized the program plan, the higher the score that is assigned to the plan. For technological viability, the differences between the technology the plan has available and what technology it needs to achieve its goals are analyzed and if the gap is not severe, the likelihood of program implementation is highly assessed since the technology risks are regarded as negligible. Therefore, the criteria employed for the logic model for an R\&D program and technological viability in PFSs can be understood as important elements that can raise the probability of predicting the outcome of the R\&D program.

With respect to elements to be considered, Balachandra and Frier (1997) who examined 19 studies out of more than 60s, analyzed and summarized 72 elements to judge the goodness of R\&D plans. Among them, technological viability, strength in marketing and technology, a competitive environment, availability of raw materials, experienced participants who have a high level of training, and good timing are suggested as crucial elements. I compare them with the elements currently used in PFSs of GRPs in table 1.

What is of interest is the possibility that the assessments of the logical and technological dimensions will have an effect on the assessment of economic dimension. As noted, the AHP method that combines the different criteria into one decisive value assumes independency across dimensions in PFSs. Survey results from experts who

9. The program logic model, a representative tool for tracking benefits that follow from the implementation of a program, has been employed during the estimation stage to identify prospective benefits (McLaughlin and Jordan, 1999). This model has been widely used in many advanced countries; for instance, the R\&D professionals of the U.S. Department of Energy, with cooperation from Congress, affiliates, customers, and other stakeholders, have improved and applied this model to develop the department's research technology program and evaluate its worth (McLaughlin and Jordan, 1999). The U.S. Advanced Technology Program has also used this model to evaluate its science and technology program at the National Institute of Standards and Technology (Ruegg and Feller, 2003). On the logical perspective of program plans and management, see Astebro 2003, Costello 1983, Cooper, Edgett, and Kleinschmidt 2001, and Coldrick, Lawson, Ivey, and Lockwood 2002. 
Table 1. Comparison of Balachandra and Friar's Success Factors to those Used by PFS in Assessing GRPS

\begin{tabular}{|c|c|c|c|}
\hline \multirow{2}{*}{$\begin{array}{l}\text { Success Factors } \\
\text { Listed by Balachandra and Friar }\end{array}$} & \multirow{2}{*}{$\begin{array}{c}\text { Number } \\
\text { of } \\
\text { Related } \\
\text { Studies }\end{array}$} & \multicolumn{2}{|c|}{$\begin{array}{l}\text { Criteria Used by PFSs } \\
\text { in Assessing GRPs }\end{array}$} \\
\hline & & $\begin{array}{c}\text { R\&D } \\
\text { Logic } \\
\text { Analysis }\end{array}$ & $\begin{array}{l}\text { Technological } \\
\text { Viability }\end{array}$ \\
\hline High-level management support & 6 & $\mathrm{O}$ & \\
\hline Probability of technical success & 5 & & $\mathrm{O}$ \\
\hline Existence of market & 4 & $\mathrm{O}$ & \\
\hline Availability of raw materials & 4 & & $\mathrm{O}$ \\
\hline Need to lower cost & 4 & $\mathrm{O}$ & \\
\hline Good timing & 4 & & O \\
\hline Emphasis on marketing & 6 & $\mathrm{O}$ & \\
\hline Marketing and technology are strengths & 5 & & O \\
\hline Competitive environment & 4 & & $\mathrm{O}$ \\
\hline Technological strategy tied to business strategy & 3 & $\mathrm{O}$ & \\
\hline R\&D process well planned & 6 & $\mathrm{O}$ & \\
\hline Create, make, market interface & 4 & & O \\
\hline Experienced participants with a high level of training & 4 & & $\mathrm{O}$ \\
\hline
\end{tabular}

had participated in PFSs of GRPs as advisors indicate that $70.9 \%$ of the 151 advisors stated that the economic dimension is independent of the other dimensions, while $57.1 \%$ of research managers who are responsible for PFSs stated that there are some correlations between dimensions. ${ }^{10}$

In theory, the attractiveness of the $R \& D$ program from an economic perspective is to be judged only by the results of a cost-benefit analysis or by the cost-effectiveness of the target program. ${ }^{11}$ But if the assessment of the logic of an R\&D program and its technological viability are related to an extent to the assessment of economic feasibility,

10. For advisory group, population is 230 and response rate is $65.7 \%$. For group of research manager of PFS on GRPs, population is 14 and the response rate is $100 \%$.

11. In reality, however, many criteria are included in the decision-making process such as degree of overlap with previous programs, consistency of the program with other related government plans, stakeholders' initiatives, and earning capability, and legal and institutional risk. 
then the assessment of economic feasibility will not provide information on the economic dimension that can be used in the process of investment decision making. In other words, if the logic of the R\&D program, including technology plans, management plans, and resource allocation plans, is adequately structured and the technological risk is not severe, then the assessment of the $R \& D$ program in terms of economic benefits seems to be regarded as positive regardless of its true economic value.

To examine this possible link, I used the analysis of the logic informing the R\&D program and its technological viability as input variables in fuzzy reasoning and compared the output values with the actual economic ratings scores. If there is some breach of independency, then the poorer rating of the R\&D program's logic and its technological viability will lead to a lower score with respect to economic benefits.

\section{Fuzzification of Variables}

In order to formulate the inference tools, three crisp variables, scores of the R\&D program's logic, its technological viability, and its economic ratings need to be converted into fuzzy numbers. This constitutes the verification process of variables between 0 and 1 derived from a 9-point scale. Although various methods can be adopted in fuzzification, I fuzzify each variable into three fuzzy sets (high, normal, and low) and into triangular fuzzy numbers.

For the triangular fuzzy numbers, the maximum degree of membership is located at the representative value, and an overlapping interval was assigned as depicted in figure 1. Each fuzzy number is a convex group with a maximum membership of 1 . The maximum degree of membership of fuzzy set "high" is located at $100 \%$, which means that with respect to the logic of the R\&D program, the plan is perfectly prepared, and the maximum membership of fuzzy set "low" is located at $0 \%$, which means that no plans have been prepared. A set of "normal" is located between the two sets.

Figure 1. Fuzzification of Variables

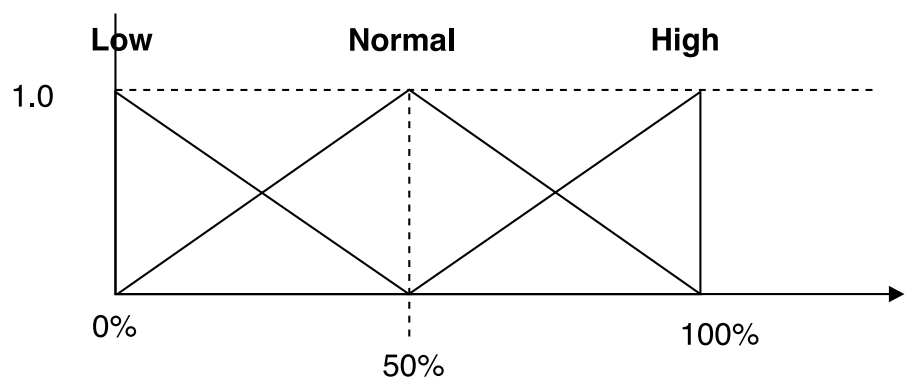


The score of the PFS is obtained using a nine-point scale $(0.1-0.9)$ with two alternatives of "unfeasible" and "feasible." Thus, the numbers between 0.1 and 0.9 are mapped inside the range of 0 to 1 with following equation.

$$
\begin{aligned}
& X_{F}=a_{1} X+b_{1} \\
& a_{1}=1.25 \\
& b_{1}=-0.125
\end{aligned}
$$

In this formula, $\mathrm{X}$ is the original value calculated using the AHP method, and $\mathrm{X}_{\mathrm{F}}$ is the value applied to the fuzzification. For example, $X=0.833$, which signifies appropriateness on the nine-point scale, goes through fuzzification to become $X_{F}=0.916$. For the triangular fuzzy numbers to be used, membership functions must consist of lines as depicted in figure 2 .

Figure 2. Lines for Fuzzy Sets

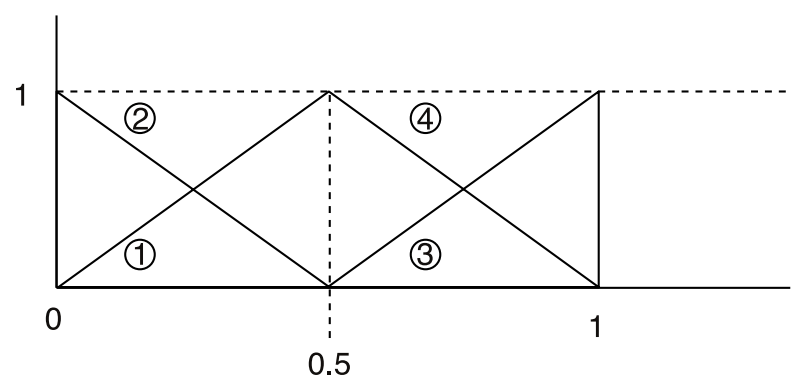

\section{Rule Base for Fuzzy Reasoning and Defuzzification}

A rule base for fuzzy reasoning is required to integrate the two input variablesthe logic of the R\&D program and its technological viability-into output variables. I divided each variable into three sets and derived nine rules from a focus group interview with experts who had experience leading PFS research teams. Table 2 shows the result of this process and reflects a kind of conditional statement on fuzzy reasoning. For instance, if the criteria of the R\&D program's logic and its technological viability are evaluated as high, then the economic criterion is rated as high, and vice versa. 
Table 2. Rule Base for Fuzzy Reasoning

\begin{tabular}{l|l|c|c|c}
\hline \multicolumn{2}{c|}{} & \multicolumn{3}{c}{ R\&D Logic Analysis } \\
\cline { 3 - 5 } \multicolumn{2}{c|}{} & Low & Normal & High \\
\hline \multirow{3}{*}{ Technological Viability } & Low & Low(C9) & Normal(C6) & Normal(C3) \\
\cline { 2 - 5 } & Normal & Low(C8) & Normal(C5) & High(C2) \\
\cline { 2 - 5 } & High & Normal(C7) & Normal(C4) & High(C1) \\
\hline
\end{tabular}

This can also be expressed as the nine inferred regulations as shown in table 3 .

Table 3. Explanation of Rule Base

\begin{tabular}{c|l}
\hline Rule & \multicolumn{1}{c}{ Explanation } \\
\hline Rule 1 & $\begin{array}{l}\text { If the R\&D logic analysis and technological viability are high, } \\
\text { then the economic aspect is high. }\end{array}$ \\
\hline Rule 2 & $\begin{array}{l}\text { If the R\&D logic analysis is high and technological viability is normal, } \\
\text { then the economic aspect is high. }\end{array}$ \\
\hline Rule 3 & $\begin{array}{l}\text { If the R\&D logic analysis is high and technological viability is low, } \\
\text { then the economic aspect is normal. }\end{array}$ \\
\hline Rule 4 & $\begin{array}{l}\text { If the R\&D logic analysis is normal and technological viability is high, } \\
\text { then the economic aspect is normal. }\end{array}$ \\
\hline Rule 5 & $\begin{array}{l}\text { If the R\&D logic analysis and technological viability are normal, } \\
\text { then the economic aspect is normal. }\end{array}$ \\
\hline Rule 6 & $\begin{array}{l}\text { If the R\&D logic analysis is normal and technological viability is low, } \\
\text { then the economic aspect is normal. }\end{array}$ \\
\hline Rule 7 & $\begin{array}{l}\text { If the R\&D logic analysis is low and technological viability is high, } \\
\text { then the economic aspect is normal. }\end{array}$ \\
\hline Rule 8 & $\begin{array}{l}\text { If the R\&D logic analysis is low and technological viability is normal, } \\
\text { then the economic aspect is low. }\end{array}$ \\
\hline Rule 9 & $\begin{array}{l}\text { If the R\&D logic analysis is low and technological viability is low, } \\
\text { then the economic aspect is low. }\end{array}$ \\
\hline
\end{tabular}

By varying the value of two input variables $\left(\mathrm{X}_{1}=\right.$ the $\mathrm{R} \& \mathrm{D}$ program's logic and $\mathrm{X}_{2}=$ technological viability), four cases are possible, and the degree of membership can be calculated through the following equations:

- In the case of I-I $\left(\mathrm{X}_{1}<0.5, \mathrm{X}_{2}<0.5\right)$

$$
\begin{aligned}
& \mu_{c 1}(Y)=\operatorname{Max}\left[\operatorname{Min}\left\{\mu_{A 1}\left(X_{1}\right), \mu_{B 1}\left(X_{2}\right)\right\}, \operatorname{Min}\left\{\mu_{A 1}\left(X_{1}\right), \mu_{B 2}\left(X_{2}\right)\right\}\right] \\
& \mu_{c 2}(Y)=\operatorname{Max}\left[\operatorname{Min}\left\{\mu_{A 2}\left(X_{1}\right), \mu_{B 1}\left(X_{2}\right)\right\}, \operatorname{Min}\left\{\mu_{A 2}\left(X_{1}\right), \mu_{B 2}\left(X_{2}\right)\right\}\right]
\end{aligned}
$$


- In the case of I-II $\left(\mathrm{X}_{1}<0.5, \mathrm{X}_{2} \geq 0.5\right)$

$$
\begin{gathered}
\mu_{c 1}(Y)=\operatorname{Min}\left\{\mu_{A 1}\left(X_{1}\right), \mu_{B 2}\left(X_{2}\right)\right\} \\
\mu_{c 2}(Y)=\operatorname{Max}\left[\operatorname{Min}\left\{\mu_{A 1}\left(X_{1}\right), \mu_{B 3}\left(X_{2}\right)\right\}, \operatorname{Min}\left\{\mu_{A 2}\left(X_{1}\right), \mu_{B 2}\left(X_{2}\right)\right\},\right. \\
\left.\operatorname{Min}\left\{\mu_{A 2}\left(X_{1}\right), \mu_{B 3}\left(X_{2}\right)\right\}\right]
\end{gathered}
$$

- In the case of II-I $\left(\mathrm{X}_{1} \geq 0.5, \mathrm{X}_{2}<0.5\right)$

$$
\begin{gathered}
\mu_{c s}(Y)=\operatorname{Max}\left\{\mu_{A 3}\left(X_{1}\right), \mu_{B 2}\left(X_{2}\right)\right\} \\
\mu_{c 2}(Y)=\operatorname{Max}\left[\operatorname{Min}\left\{\mu_{A 2}\left(X_{1}\right), \mu_{B 1}\left(X_{2}\right)\right\}, \operatorname{Min}\left\{\mu_{A 2}\left(X_{1}\right), \mu_{B 2}\left(X_{2}\right)\right\},\right. \\
\left.\operatorname{Min}\left\{\mu_{A 3}\left(X_{1}\right), \mu_{B 1}\left(X_{2}\right)\right\}\right]
\end{gathered}
$$

- In the case of II-II $\left(\mathrm{X}_{1} \geq 0.5, \mathrm{X}_{2} \geq 0.5\right)$

$$
\begin{aligned}
& \mu_{c 2}(Y)=\operatorname{Max}\left[\operatorname{Min}\left\{\mu_{A 2}\left(X_{1}\right), \mu_{B 2}\left(X_{2}\right)\right\}, \operatorname{Min}\left\{\mu_{A 2}\left(X_{1}\right), \mu_{B 3}\left(X_{2}\right)\right\}\right] \\
& \mu_{c s}(Y)=\operatorname{Max}\left[\operatorname{Min}\left\{\mu_{A 3}\left(X_{1}\right), \mu_{B 2}\left(X_{2}\right)\right\}, \operatorname{Min}\left\{\mu_{A 3}\left(X_{1}\right), \mu_{B 3}\left(X_{2}\right)\right\}\right]
\end{aligned}
$$

Defuzzification is a process for converting the fuzzy output into a single value that can be compared. In this study, the centroid method is employed, using following equation.

$$
C_{x}=\frac{\int x \mu(x) d x}{\int \mu(x) d x}
$$

\section{RESULTS}

\section{Comparison with Actual Results}

As mentioned before, I compared the values derived from fuzzy reasoning using the scores of the R\&D logic model analysis and its technological viability with the actual values of the economic ratings. First, I compared the signs of values derived

Table 4. Comparison between Values Derived from Fuzzy Reasoning and Actual Scores

\begin{tabular}{l|l|c|c|c}
\hline \multirow{2}{*}{} & \multicolumn{3}{|c}{ Prediction from Fuzzy Inference } \\
\cline { 3 - 5 } & $\begin{array}{c}\text { Inclines toward } \\
\text { "Feasible" }\end{array}$ & $\begin{array}{c}\text { Inclines toward } \\
\text { "Unfeasible" }\end{array}$ & Total \\
\hline \multirow{3}{*}{ Actual Rating } & Inclines toward "Feasible" & 27 & 1 & 28 \\
\cline { 2 - 5 } & Inclines toward "Unfeasible" & 3 & 20 & 23 \\
\cline { 2 - 5 } & Total & 30 & 21 & 51 \\
\hline
\end{tabular}


Table 5. Results of Comparison

Analysis of Variance

\begin{tabular}{c|c|c|c|c}
\hline & $\mathrm{R}$ & $\mathrm{R}$-Squared & $\mathrm{F}$ & $\mathrm{P}$-value \\
\hline Value & 0.850 & 0.722 & 127.1 & 0.000 \\
\hline
\end{tabular}

Coefficient

\begin{tabular}{c|c|c|c|c}
\hline & Value & Standard Error & $\mathrm{t}$ & P-value \\
\hline$\beta_{0}$ & -0.670 & 0.105 & -6.386 & 0.000 \\
\hline$\beta_{1}$ & 2.299 & 0.204 & 11.275 & 0.000 \\
\hline
\end{tabular}

from fuzzy reasoning with the actual scores. If there are too many cases in which the values tend in opposing directions, we cannot give much credibility to the result generated by the fuzzy inference system.

As table 4 indicates, the inference results and actual ratings are identical in 47 out of 51 cases $(92.2 \%)$, and the probability of making misjudgments using fuzzy reasoning is only $7.8 \%$.

Second, in order to examine the closeness of the relationship, I performed a simple regression analysis. Here, the values produced from fuzzy reasoning become independent variables, and the actual scores serve as dependent variables. The result is presented in the table 5 .

$$
\mathrm{Y}=\beta_{0}+\beta_{1} X_{1}
$$

As can be seen, the values produced by fuzzy reasoning are close enough to the actual ones. The estimated coefficient is statistically significant and the linearity seems to be secured with a high $\mathrm{R}^{2}$.

\section{Analysis with Classification}

It is possible to get different results via fuzzy reasoning using actual scores from the $R \& D$ logic model analysis and its technological viability as input variables. One way that this could happen is if one focuses on a specific R\&D type in one's analysis; the impact of the R\&D program's logic and technological viability may be different with respect to benefits depending on what type of an R\&D program it is.

Although there are no specific rules for classifying R\&D types, one classification that is widely used follows the phases of R\&D. For instance, basic research aims to acquire new knowledge, and development research aims to produce or alter new 
Table 6. Classification of Government R\&D Programs

\begin{tabular}{c|l}
\hline Division & \multicolumn{1}{c}{ Explanation } \\
\hline Type 1 & $\begin{array}{l}\text { Large-sized, bottom-up type (public subscription) program focusing basic research; } \\
\text { form of economic analysis used is cost-effectiveness analysis }\end{array}$ \\
\hline Type 2 & $\begin{array}{l}\text { Large-scale industrial technology development program with over KRW 400 billion; } \\
\text { form of economic analysis used is cost-benefit analysis with clear target markets }\end{array}$ \\
\hline Type 3 & $\begin{array}{l}\text { System development, which includes facilities or equipment for basic or applied } \\
\text { research }\end{array}$ \\
\hline Type 4 & $\begin{array}{l}\text { Bottom-up type (public subscription) program oriented toward basic and fundamental } \\
\text { research; form of economic analysis used is cost-effectiveness analysis }\end{array}$ \\
\hline Type 5 & $\begin{array}{l}\text { Bottom-up type (public subscription) program that focuses on industrial technology } \\
\text { development; form of economic analysis used is cost-benefit analysis }\end{array}$ \\
\hline Type 6 & Other programs \\
\hline
\end{tabular}

products and process. ${ }^{12}$ The implication of this classification is that since the outputs of the various phases of R\&D are different, they may affect the program's overall economic impact, which may be reflected in the rating process of PFSs. Following Park (2009), who examined many cases of ex-ante evaluation of GRPs, I applied six types of classification, as shown in table 6 .

Table 7 presents a comparison between the values derived from fuzzy reasoning and the actual economic ratings of the proposed classification types. For types 2, 3, and 6, fuzzy reasoning produces larger values than the actual economic ratings, whereas for types 1,4 , and 5 , whose budget size are relatively small, the fuzzy inference values are smaller. Since the differences among groups are not statistically significant, however, we cannot reject the null hypothesis that the degrees of error in the values derived via fuzzy reasoning are identical across types. In other words, it seems that we can apply fuzzy reasoning regardless of R\&D types.

Another point that requires attention is the difference in methods of assessing economic feasibility. In the PFSs of GRPs, this assessment is not limited to a cost-benefit analysis. If it is not possible to secure the information needed to calculate a program's precise benefits or ascertain its contribution to benefit creation or to define the range of program benefits a cost-effectiveness analysis rather than cost-benefits analysis can be made.

12. The OECD's Frascati Manual suggests another classification wherein R\&D programs are divided into public health and the environment, economic development, space, and national defense groups. 
Table 7. Difference between Calculated Values and Real Scores

\begin{tabular}{c|c|c}
\hline Classification & Average & Number of Programs \\
\hline Type 1 & 0.00033 & 6 \\
\hline Type 2 & -0.01536 & 14 \\
\hline Type 3 & -0.09888 & 4 \\
\hline Type 4 & 0.07375 & 6 \\
\hline Type 5 & 0.08883 & 13 \\
\hline Type 6 & -0.03085 & 51 \\
\hline Total & -0.01131 &
\end{tabular}

In a cost-benefit analysis, total costs and benefits are calculated as the sum of individual costs and benefits in monetary terms, and the ratio of the two values (B/C ratio) has a clear meaning to decision makers. By contrast, in a cost-effectiveness analysis, total costs of program implementation are calculated, but program effectiveness (or benefits) cannot be converted into monetary values, which means that there is no single $\mathrm{B} / \mathrm{C}$ ratio. In this case, the analysis does not have an absolute standard such as 1 like a cost-benefit analysis does, and therefore it is usually used in selecting between alternatives. In the cases of the PFSs of GRPs used in this article, 31 of them, which I refer to as group 1, conducted a cost-benefit analysis, and 20 of them, which I refer to as group 2 , conducted a cost-effectiveness analysis that produced differences in the amount and quality of information available for decision making. The descriptive statistics of actual economic rating scores and fuzzy inference values for each group are presented in table 8 and the mean-difference test results are shown in table 9.

Table 8. Economic Ratings by Method of Economic Analysis

\begin{tabular}{c|l|c|c|c}
\hline Group & Economic Analysis Method & $\begin{array}{c}\text { Number } \\
\text { of Cases }\end{array}$ & $\begin{array}{c}\text { Average Economic } \\
\text { Rating Score }\end{array}$ & $\begin{array}{c}\text { Standard } \\
\text { Deviation }\end{array}$ \\
\hline Group 1 & Cost-benefit analysis & 31 & 0.502 & 0.263 \\
\hline Group 2 & Cost-effectiveness analysis & 20 & 0.485 & 0.203 \\
\hline
\end{tabular}

Table 9. Comparison between Two Groups in Economic Ratings

\begin{tabular}{l|c|c}
\multicolumn{1}{c|}{ Division } & $\mathrm{t}$-value & Significance Probability \\
\hline Equal variances assumed & 0.255 & 0.800 \\
\hline Equal variances not assumed & 0.270 & 0.788 \\
\hline
\end{tabular}


Table 10. Difference between Their Economic Ratings and Values Derived from Fuzzy Reasoning by Two Groups

\begin{tabular}{c|l|c|c|c}
\hline Group & Economic Analysis Method & Number of Cases & Mean & Standard Deviation \\
\hline Group 1 & Cost-benefit analysis & 31 & -0.00597 & 0.1869 \\
\hline Group 2 & Cost-effectiveness analysis & 20 & -0.0196 & 0.1467 \\
\hline
\end{tabular}

Table 11. Fuzzy Inference Values of the Two Groups

\begin{tabular}{c|c|c}
\multicolumn{1}{c|}{ Division } & t-value & Significance Probability \\
\hline Equal variances assumed & 0.276 & 0.784 \\
\hline Equal variances are not assumed & 0.290 & 0.773 \\
\hline
\end{tabular}

Figure 3. Comparison between the Two Groups: In Terms of the Difference between Their Economic Ratings and Values Derived from Fuzzy Reasoning

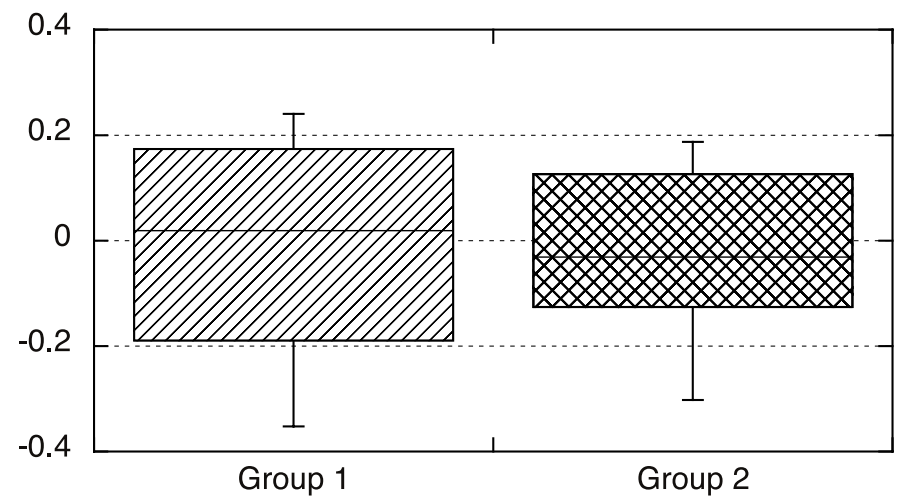

As tables 10 and 11 show, however, there is no statistically significant difference between the two groups with respect to the method of economic analysis, and that fact allows us to discount any possibility of influence of the different methods of economic analysis.

\section{CONCLUSION}

This study has examined the adequacy of the ex-ante evaluation (PFS) of GRPs, using fuzzy reasoning to see whether the basic assumption of the independence of the economic feasibility analysis holds. Because in theory economic analysis in PFSs is 
based on a cost-benefit approach, they can be seen as belonging to a normative and reasonable decision-making domain. In fact, economic feasibility plays the single most important role in the overall decision-making process. In practice, however, there are many constraints that do not permit cost-benefit or cost-effectiveness analysis to be strictly implemented. In particular, the practice of economic analysis seems to partially rely on information derived from other dimensions, such as the R\&D program's logic and its technological viability, as a means of compensating for the lack of economic information with respect to the expected benefits and costs.

To verify the possible link between these dimensions and the economic one, I drew on fuzzy reasoning, using the scores of the $R \& D$ logic analysis and of its technological viability as the input variables and the pseudovalues of the economic ratings as the output variables. Then, I compared the output values derived from fuzzy reasoning with the actual economic ratings for each of 51 PFS cases and found a statistically significant relationship: the results derived through fuzzy reasoning are not exactly the same as those from the economic analysis, but they are close enough. For instance, I found that in 47 out of 51 cases the fuzzy reasoning values and actual values were identical, $90 \%$ of those being feasible cases and $95.2 \%$ being unfeasible.

Discussions with experts and advisors who participated in previous PFSs suggest a plausible reason for correlation; there are many small group meetings during the process of a PFS in which information about one dimension is shared to compensate for the lack of information about other dimensions. Although such information sharing is prudent, it is also the main channel by which the independence of the economic analysis is mitigated. Furthermore, due to the nature of R\&D programs, logical and technological adequacy seem to lead to expectations of economic benefits and not vice versa.

There are two possible alternatives we can suggest. First, sever the potential link between economic and noneconomic dimensions with extraneous regulations. But although such a measure might solve the problem of interdependency, the problem of overcoming the lack of information would become more critical. Second, instead of ignoring reality, PFSs could take the possible linkage among the various dimensions formally into account in the economic analysis. Considering, for instance, information related to noneconomic dimensions as a risk (or probability) in making an economic prediction is reasonable in many situations. The question is whether to make this procedure explicit or implicit.

It is desirable to make a decision about a large-scale long-term investment based on the most complete information. Thus, the limitations of economic analysis should be clarified, and a comprehensive analysis that uses all the available data in a systematic way should be considered. From this perspective, it is necessary to develop analytical 
modules of collecting, analyzing, and combining data to create an information pool. In the meanwhile the fuzzy reasoning tools suggested in this study can be used to examine whether the various elements share connections and if so, to what extent.

A final caution is in order with respect to fuzzy inference as used in this study. Only two representative variables were taken as input variables, and triangular fuzzy numbers were distinguished as three fuzzy sets, which limited the rule base to 9 rules. It would be desirable to develop a more precise inference tool in the future by employing more detailed information and applying multiple variables using a standardized measurement scale. For this, further theoretical and empirical work is necessary to streamline communication between experts from various fields such as technology, economics, and policy.

\section{REFERENCES}

Astebro, T. 2003. The return to independent invention: Evidence of unrealistic optimism, risk seeking or skewness loving? Economic Journal, 113 (484): 226-239.

Balachandra, R., \& Friar, J. H. 1997. Factors for success in R\&D projects and new product innovation: A contextual framework. Engineering Management, 44 (3): 276-287.

Chang, S., \& Zadeh, L. 1972. On fuzzy mapping and control. IEEE Transactions on Systems, Man and Cybernetics, 2: 30-42.

Cho, K. T., \& , Kwon C. S. 2002. Development of a cross-impact hierarchical model for deciding technology priority. Journal of the Korean Operations Research and Management Science Society, 27 (1): 1-17.

Coldrick, S., Lawson, C. P., Ivey, P. C., \& Lockwood, C. 2002. A decision framework for R\&D project selection. Engineering Management Conference, 1: 413-418.

Cooper, R., Edgett, S., \& Kleinschmidt, E. 2001. Portfolio management for new product development: Results of an industry practices study. R\&D Management, 31 (4): 361-380.

Costello, D. 1983. A practical approach to R\&D project selection. Technological Forecasting and Social Change, 23 (4): 353-368.

Hwans, S. W. 2004. Building the method for economic analysis of R\&D programs based on type. STEPI Report.

Kim, T. Y., \& Kim, S. B. 2004. Theory and practice of cost-benefit analysis: Evaluation of public programs and the impact of regulation. Parkyoungsa.

Lee, J. C. 1996. Management of task flow of the flexible flow system utilizing fuzzy logic control. Journal of Management Science, 5: 225-252. 
Lilien, G. L., \& Yoon, E. 1989. Determinants of new industrial product performance: A strategic re-examination of the empirical literature. Engineering Management, 36 (1): 3-10.

Mamdani, E. H. 1974. Application of fuzzy algorithms for control of simple dynamic plant. Proceedings of the IEEE, 121 (12): 1585-1588.

Mansfield E. 1991. Academic research and industrial innovation. Research Policy, 20: $1-12$.

McLaughlin, J. A., \& Jordan, G. B. 1999. Logic models: A tool for telling your programs performance story. Evaluation and Program Planning, 22 (1): 65-72.

Morris, P. 1990. The strategic management of projects. Technology in Society, 12 (2): 197-215.

OECD. 2007. Assessing the socio-economic impacts of the framework programme. OECD DSTI Report.

Park, H. 2000. Multicriteria analysis plan needed for implementation of preliminary feasibility study. KDI Report.

Park, J. Y. 2009. Research on an economic analysis method that relies on classified characteristics of R\&D logics. Graduate school of Public Administration, Seoul National University.

Pinto, J., \& Slevin, D. P. 1988. The project champion: Key to implementation success. Project Management Journal, 1 (1): 15-20.

Priyantha, D. C., Wijayatunga, K. S., Fernando, W. J. L. S., Shrestha, R. M., \& Attalage, R.A. 2006. Strategies to overcome barriers for cleaner generation technologies in small developing power systems: Sri Lanka case study. Energy Conversion \& Management, 47 (9-10): 179-1191.

Ramanathan, R. 2002. Successful transfer of environmentally sound technologies for greenhouse gas mitigation: A framework for matching the needs of developing countries. Ecological Economics, 42 (1-2): 117-129.

Ruegg R., \& Feller I. 2003. A toolkit for evaluating public R\&D investment: Models, methods, and findings from ATP's first decade. NIST GCR 03-857.

Yang, H. S. 2010. Study of the preliminary feasibility study of R\&D programs. Korean Journal of Policy Analysis and Evaluation, 20 (2): 77-101.

Yang, S. G., Moon, S. J., Ahn, D. K, \& Kim, S. J. 2007. Analysis on cost difference in research funding. Journal of Accounting and Finance, 26 (2): 197-219.

Yusuff, R. M., Yee, K. P., \& Hashmi, M. S. J. 2001. A preliminary study on the potential use of the analytical hierarchical process to predict advanced manufacturing technology implementation. Robotics and Computer Integrated Manufacturing, 17 (5): 421-427. 